\title{
EMBATES EM TORNO DO CONCEITO DE CULTURA CORPORAL: GÊNESE E TRANSFORMAÇÕES
}

\author{
Marcos Garcia Neira \\ Universidade de São Paulo, São Paulo, São Paulo, Brasil \\ Lilian Cristina Gramorelli \\ Colégio Marista Arquidiocesano, São Paulo, São Paulo, Brasil
}

\begin{abstract}
Resumo
A presente cartografia descreve e analisa as influências sofridas pelo conceito de cultura corporal desde o seu surgimento. Concebido num contexto de abertura política, inspirou-se nas teorias críticas e foi decisivo na mudança paradigmática que o ensino da Educação Física experimentou a partir da década de 1980. Abrandada pelos estudos antropológicos e, posteriormente, enfraquecida pelo discurso neoliberal dos anos 1990, a noção de cultura corporal teve suas forças renovadas no século XXI, mediante a contribuição das teorias pós-críticas da educação.
\end{abstract}

Palavras-chave: Educação física. Cultura Corporal. Teorias Críticas. Teorias Pós-Críticas.

\section{Introdução}

A expressão "cultura corporal" tornou-se corriqueira na literatura específica da Educação Física, com especial destaque para o campo pedagógico. O uso indiscriminado em trabalhos de todos os tipos contribuiu para o esmorecimento do seu potencial crítico, ao vinculá-la a propostas de ensino e a terrenos epistemológicos de todos os matizes. O estudo realizado por Gramorelli (2014) corrobora essa assertiva ao apontar o mesmo fenômeno nas propostas curriculares estaduais. Apesar de objetivarem a formação de sujeitos diferentes, os documentos oficiais tomam de empréstimo o termo e atribuem-lhe significados distintos.

A constatação desse fato fez surgir o interesse de analisar a literatura em busca dos sentidos originalmente atribuídos ao conceito, relacionando-os ao contexto sociopolítico, assim como apontar suas novas significações e os campos conceituais que as inspiram.

Apesar dos alertas de Bracht (1999) acerca das distinções que envolvem a expressão e que se refletem em ações pedagógicas, a área parece pouco sensível ao fato de que seu emprego a torto e direito pode ter como objetivo simplesmente envernizar o discurso convencional, propagandeando-o como novo. Advém daí a necessidade de elucidar o assunto, enfatizando que tematizar a cultura corporal nas aulas de Educação Física implica recorrer a referenciais teóricos e a encaminhamentos didáticos específicos, afastando-se daqueles que caracterizam as propostas inspiradas nos princípios psicobiológicos. 
Seguindo o raciocínio de Silva (1999), os significados atribuídos às coisas do mundo resultam de lutas pelo poder de definir o que elas são e o que elas não são. Como as disputas ocorrem em meio ao dinamismo cultural, é razoável supor que ideias, conceitos e concepções sofram transformações para adequar-se aos novos contextos sociais. Consequentemente, o estudo aqui relatado não tem a menor intenção de atribuir um único e verdadeiro sentido ao termo; outrossim, buscou simplesmente traçar uma cartografia ${ }^{1}$, identificando os possíveis vetores de força que influenciaram e influenciam a sua significação.

\section{As teorias críticas e a cultura corporal}

A incorporação do conceito de cultura corporal pela Educação Física deu-se sob a égide das teorias críticas. O significado inicialmente atribuído à expressão decorre de um contexto político e social de abertura democrática e luta pela modificação do papel da escola. Também é concomitante à intenção de realçar uma nova função social do componente contraposta ao ensino tradicional. Com a cultura corporal, o objeto de estudo da Educação Física transformou-se e ensejou práticas pedagógicas e intenções educativas afastadas daquelas propaladas pelas vertentes que elegeram o exercício físico e, mais tarde, o movimento como objetos de ensino.

A primeira menção em língua portuguesa ocorre na década de 1980. As mudanças sociais e educacionais daquele período revelaram o anacronismo que caracterizava o ensino da Educação Física, que extraía da biologia e da psicologia do desenvolvimento seus conceitos fundantes. Nessa visão, o movimento se apresentava como algo neutro, isento de qualquer influência político-ideológica. Mediante um trabalho pedagógico voltado para o desenvolvimento dos domínios do comportamento, os conteúdos do componente exerciam mera função instrumental.

A mudança paradigmática desencadeada pelas análises da escola pautadas nas teorias crítico-reprodutivistas e o diálogo cada vez mais intenso com as ciências humanas desestabilizaram os alicerces biologicistas, o que levou a Educação Física a adotar uma compreensão do movimentar-se humano como fenômeno histórico-cultural e eleger a cultura corporal como objeto de estudo.

Entre os autores brasileiros, Bracht (1989) inaugurou o uso da expressão:

No seu sentido "restrito" o termo Educação Física abrange as atividades pedagógicas tendo como tema o movimento corporal que tomam lugar na instituição educacional. No seu sentido "amplo" tem sido utilizado para designar, inadequadamente a meu ver, todas as manifestações culturais ligadas à ludomotricidade humana, que no seu conjunto parece-me serem melhor abarcadas com termos como cultura corporal ou cultura de movimento (p. 13).

Nesse ensaio, denunciou a subordinação da Educação Física aos sentidos que as instituições militar e esportiva atribuíram às práticas corporais e procurou reposicionar a área, definindo-a como um campo de estudos que abrange todas as manifestações abarcadas pelo conceito de cultura corporal, em detrimento das correntes que procuravam restringi-la ao estudo do movimento.

Em textos oficiais, a expressão foi empregada pela primeira vez em 1989, com a publicação do documento denominado Contribuição ao debate do currículo em Educação Física: uma proposta para a escola pública, pelo estado de Pernambuco, durante o governo democrático de Miguel de Arraes Alencar. Vieira (2010) constatou que o caráter inovador da

\footnotetext{
${ }^{1}$ No sentido foucaultiano, cartografia é um estudo das relações de força que compõem um campo específico de experiências.
} 
proposta, ao abordar o ensino da Educação Física numa dimensão diferente daquelas centradas no desempenho motor, serviu como referência para a construção dos currículos do Distrito Federal, de Minas Gerais e São Paulo, em princípios dos anos 1990.

No currículo oficial pernambucano, a cultura corporal integra o objetivo da Educação Física, pois ressalta o estudo da expressão corporal como linguagem. Também enfatiza a apropriação do conhecimento sócio-histórico, a compreensão das técnicas de movimento e os significados conferidos aos temas da cultura corporal. No documento, cultura corporal é o resultado da tematização de atividades expressivas corporais como jogos, danças, lutas, exercícios ginásticos, esportes, malabarismos, mímica, entre outros.

Antes de passar a impressão de que se trata de mera questão semântica, é importante situar o contexto e elucidar o significado do surgimento desse conceito. À época, sob o jugo da Lei $n^{\circ} 5.692 / 71$ e do Decreto $n^{\circ}$ 69.450/71, a Educação Física era concebida como atividade e suas aulas deveriam restringir-se ao ensino de técnicas corporais. A imensa maioria dos professores em atuação havia sido formada em cursos pautados na Resolução CFE $\mathrm{n}^{\circ}$ 69/1969, que fixava o currículo mínimo da licenciatura ${ }^{2}$ em poucas disciplinas agrupadas em fundamentos biológicos, didáticos ${ }^{3}$ e gímnico-desportivos. Afinal, a sociedade esperava que a Educação Física cumprisse bem o seu papel de disseminar os códigos esportivos às novas gerações.

No âmbito internacional, mais especificamente na Alemanha, as consequências desse processo haviam sido apontadas por Dieckert et al. (1985), enquanto no Brasil Medina (1983), Bracht (1986) e Ferreira (1987) convidavam a Educação Física a rever seus pressupostos e mudar de direção. Numa sociedade recém-saída da ditadura e em pleno movimento Diretas Já, as aulas de Educação Física não poderiam mais parasitar a escola, dificultando a formação de sujeitos desejada para uma democracia.

A expressão "cultura corporal" emergiu, então, num contexto sociopolítico bastante específico, numa conjuntura de crítica à esportivização hegemônica:

Foi a partir das críticas realizadas por Dieckert (1985) à visão de esporte de alto nível que esse conceito se fez presente. $\mathrm{O}$ autor buscava uma Educação Física mais humana dentro da concepção do 'Esporte para Todos', onde fosse discutida e criada uma 'nova antropologia' que colocasse como centro da questão 'uma cultura corporal própria do povo brasileiro' (SOUZA JUNIOR et al., 2011, p. 395).

Em 1992, um coletivo de autores trouxe à tona o reducionismo biológico e psicológico que nublava a Educação Física convencional e anunciaram que o conceito de cultura corporal decorria da existência de uma produção humana corpórea transformada em patrimônio cultural.

A Educação Física é uma disciplina que trata, pedagogicamente na escola, do conhecimento de uma área aqui denominada de cultura corporal. Ela será configurada com temas ou formas de atividades, particularmente corporais, como as nomeadas anteriormente: jogo, esporte, ginástica, dança ou outras, que constituirão seu conteúdo. $\mathrm{O}$ estudo desse conhecimento visa apreender a expressão corporal como linguagem (SOARES et al., 1992, p.61).

\footnotetext{
${ }^{2} \mathrm{O}$ diploma concedido era de Licenciatura Plena em Educação Física. O bacharelado na área foi criado a partir da Resolução CFE nº 03/1987.

${ }^{3}$ Estipulados pela Resolução CFE no 09/1969, limitavam-se à Psicologia do Desenvolvimento, Estrutura e Funcionamento do Ensino de $1^{\circ}$ e $2^{\circ}$ Graus e Didática.
} 
Pautados no materialismo histórico, os autores defendiam que a seleção e a organização dos conteúdos da aula deveriam promover a leitura da realidade brasileira, buscando uma aproximação com a prática social e cultural estabelecida, o que, de certa maneira, rompia com os pressupostos norteadores vigentes. Nessa proposta, a cultura corporal era o conteúdo próprio da Educação Física.

Na opinião de Neira e Nunes (2006), a contribuição dessa obra não se encerra na definição do objeto de estudo da área. Sua ousadia consistiu em pontuar os interesses embutidos no ensino tradicional do componente. Além disso, inspirada no trabalho de Saviani (1991), marcou definitivamente a área quando alertou que qualquer consideração sobre a pedagogia mais apropriada deve versar não somente sobre como ensinar, mas também sobre como elaborar conhecimentos, valorizando a contextualização dos fatos e a retomada do processo histórico.

É certo que o diálogo da Educação Física com as teorias críticas da educação apresentou um novo quadro de perspectivas pedagógicas diferentes das concepções até então presentes na área, possibilitando a compreensão de que os conteúdos que se ensinavam encontravam-se marcados pelas relações sociais e transmitiam a ideologia dominante.

As teorias críticas questionaram os objetivos e meios adotados pela educação escolar e, consequentemente, pela Educação Física, que incorporou o conceito de cultura corporal como forma de expressar outra visão do componente, evidenciando que algo mais acontecia nas aulas para além da fixação de gestos técnicos padronizados e execução de exercícios voltados para a melhoria da aptidão física. Com a contribuição das teorias críticas, o componente passou a situar as práticas corporais no contexto social mais amplo, entendendo-as como suportes nos quais se fixavam os signos da classe social em que foram criadas e recriadas.

A disseminação do termo "cultura corporal" foi necessária para desnaturalizar o ensino da Educação Física, já que passou a situar social e historicamente seu objeto de estudo na tentativa de superar a neutralidade e as concepções apolíticas até então em vigor. Seu papel se distanciou da formação do corpo saudável ou habilidoso projetado pelos grupos mais bem situados na pirâmide social. Mas, para além das teorias críticas, o conceito sofreria outras influências.

\section{Antropologia, Parâmetros Curriculares Nacionais e a cultura corporal}

Em meados dos anos 1990, a noção de cultura corporal foi nutrida pelo diálogo que a Educação Física travou com a antropologia, através, principalmente, das obras de Daolio (1995 e 1997), que, apoiado na perspectiva interpretativa de Cliford Geertz, incorporou ao conceito de cultura corporal seus sentidos e significados, ampliando consequentemente a forma de compreender o conceito e de atuar pedagogicamente.

Por um lado, o olhar antropológico foi decisivo para que as práticas corporais fossem compreendidas como textos produzidos pela linguagem corporal, passíveis, portanto, de múltiplas leituras, a depender dos significados que lhes são atribuídos. Mas também há que se dizer que essa visão se mostrou preocupada exclusivamente com o etnocentrismo que contamina o olhar daquele que se debruça sobre a produção cultural de outrem, sem chamar a atenção para as relações de poder que atravessam tanto a produção quanto a leitura de qualquer texto cultural. Tudo indica, portanto, que a disseminação dessa perspectiva antropológica possa ter diminuído o potencial crítico que influenciou a gênese do conceito. $O$ golpe fatal, no entanto, ainda estava por vir.

No final da mesma década, a expressão "cultura corporal" se viu consagrada nos Parâmetros Curriculares Nacionais (BRASIL, 1997, 1998 e 1999). Entretanto, as concepções apolíticas da Educação Física presentes nesses documentos conferiram uma sobrevida, inclu- 
sive, aos fundamentos psicobiológicos e à educação para a saúde. Essa alquimia parece ter enterrado de vez toda a criticidade que fez surgir o conceito.

Entende-se a Educação Física como uma área de conhecimento da cultura corporal de movimento e a Educação Física escolar como uma disciplina que introduz e integra o aluno na cultura corporal de movimento, formando o cidadão que vai produzi-la, reproduzi-la e transformá-la, instrumentalizando-o para usufruir dos jogos, dos esportes, das danças, das lutas e das ginásticas em benefício do exercício crítico da cidadania e da melhoria da qualidade de vida (BRASIL, 1998, p. 29).

Gramorelli (2007) apontou a confusão conceitual presente nos PCN. O texto referente aos primeiros anos do Ensino Fundamental apresenta a Educação Física como cultura corporal sem explicitar os fundamentos que a sustentam; a proposta que abarca os anos finais mistura várias tendências da área e entende a Educação Física como cultura corporal de movimento. Por sua vez, o material voltado ao Ensino Médio apoia-se nas teorias biológicas para defender a ideia de educação que promova a adoção de um estilo de vida fisicamente ativo, mas anuncia que o aluno deve ter sólidos conhecimentos sobre a cultura corporal.

Os documentos oficiais fomentam uma visão cognitivista da cultura corporal, ao sugerir o construtivismo pedagógico como concepção educativa, a tipologia de conteúdos como forma de organização dos conhecimentos e o desenvolvimento de competências como finalidade da escola. Lopes e Macedo (2011) denunciam o viés funcional camuflado nessas propostas. Vale perguntar se poderia ser diferente, haja vista que os PCN foram gestados em pleno governo neoliberal.

Não obstante, com a chegada do século XXI, o conceito de cultura corporal recebeu outras influências. Diante das novas configurações sociais, o debate educacional enriqueceuse com o aporte das teorias pós-críticas (SILVA, 2011). Geradas no calor dos movimentos que questionaram os desígnios culturais, políticos e econômicos postos pela Modernidade, as teorias pós-críticas ampliaram as análises realizadas pelas teorias críticas com a indagação das pretensões totalizantes das grandes narrativas, do sujeito autônomo e centrado do projeto moderno e dos processos de dominação e poder baseados exclusivamente nas divisões de classe.

As teorias críticas chamaram a atenção para as regras e conteúdos transmitidos pela escola capitalista, questionaram o modo como os conhecimentos são produzidos e validados socialmente, apontaram as injustiças dos modelos reprodutores dos sistemas sociais, denunciaram a educação como campo em que ideologias se confrontam para impor sua lógica. As teorias pós-críticas, ao seu tempo, realizam um deslocamento na maneira de conceber a pedagogia, que passou a ser vista como prática social, logo, cultural, resultante da linguagem, dos textos, dos discursos, das relações de poder, da história e dos processos de subjetivação.

Nas teorias pós-críticas, o poder torna-se descentrado, espalhado por toda a rede social. O conhecimento não é exterior ao poder, é parte inerente. A subjetividade é social, o que contraria a noção crítica da existência de um núcleo subjetivo que precisa ser restaurado. As teorias pós-críticas ampliam e, ao mesmo tempo, modificam aquilo que as teorias críticas ensinaram:

Em contraste com as teorias críticas, as teorias pós-críticas não limitam a análise do poder ao campo das relações econômicas do capitalismo. Com as teorias pós-críticas, o mapa do poder é ampliado para incluir os processos de dominação centrados na raça, na etnia, no gênero e na sexualidade (SILVA, 2011, p. 149). 
As dificuldades de compreender a paisagem social que se constituiu no final do século $\mathrm{XX}$ evidenciaram o esgotamento das teorias existentes e anunciaram o surgimento de campos conceituais como o pós-modernismo, pós-estruturalismo, multiculturalismo e Estudos Culturais, entre outros. As temáticas que afligem os sujeitos contemporâneos tornaram necessárias categorias de análise que permitam descortinar as relações travadas entre poder e identidade e entre a escola e a sociedade pós-moderna.

O pós-modernismo é um movimento intelectual que proclama uma nova época histórica, a Pós-modernidade, radicalmente diferente da anterior, a Modernidade (SILVA, 2011). Na Pós-modernidade, questionam-se os princípios e pressupostos do pensamento social e político estabelecidos e desenvolvidos a partir do Iluminismo. O sujeito que tinha na Modernidade sua identidade estável e bem definida está se tornando fragmentado, composto não de uma, mas de várias identidades (HALL, 2006). O pós-modernismo coloca em suspeita os princípios das "grandes narrativas" da Modernidade, pois elas nada mais são que a expressão da vontade de domínio e controle dos modernos. Também rejeita a divisão entre "alta" e "baixa" cultura, entre conhecimento científico e conhecimento cotidiano (SILVA, 2011).

O diálogo da Educação Física com os referenciais pós-modernos possibilita outras formas de constituição da experiência pedagógica, descentralizando o papel do conhecimento científico e valorizando os saberes pertencentes ao senso comum, à cultura popular ou à cultura paralela à escola. Ademais, os pressupostos do pós-modernismo favorecem a construção de atividades de ensino que reconhecem e valorizam as múltiplas identidades presentes na sociedade, colocando em xeque a promessa educacional moderna: a libertação do homem através do conhecimento científico.

O pós-estruturalismo, por sua vez, pode ser entendido como continuidade e, ao mesmo tempo, transformação do pensamento estruturalista ${ }^{4}$. Mais precisamente, o pós-estruturalismo revela os problemas enfrentados pela visão estruturalista da linguagem ${ }^{5}$ quando se propõe a explicitar a complexidade com que homens e mulheres "leem" e interpretam a realidade.

O pós-estruturalismo toma a linguagem como algo não fixo e, portanto, não mais centrado na correspondência inquestionável entre um signo e seu significado. A linguagem é compreendida como movimento, em constante fluxo, sempre indefinida, sempre adiada e imersa em relações de poder. Um olhar pós-estruturalista para o ensino da Educação Física permite a inclusão de todas as tradições culturais para que muitas vozes possam ser representadas, pois, nele, não se discute ou se atribui valoração a esta ou aquela prática corporal. Uma proposta de Educação Física inspirada no pós-estruturalismo considera legítimas não somente todas as manifestações da cultura corporal, como também problematiza todos os significados produzidos sobre elas e a partir delas.

A análise do contexto atual também se beneficiou com o surgimento do multiculturalismo. Trata-se de um movimento de reivindicação dos grupos dominados no interior dos países do Hemisfério Norte para terem suas formas culturais socialmente reconhecidas e representadas (SILVA, 2011). O grande fluxo migratório em direção aos países ricos ocasionou conflitos devidos ao convívio forçado de diferentes culturas. De certa maneira, isso incitou os representantes das minorias subjugadas a criarem um instrumento de luta, o chamado multiculturalismo.

O multiculturalismo levanta uma importante questão ao transferir para o terreno político a compreensão da diversidade que, por muito tempo, esteve restrita à antropologia. Nesse

\footnotetext{
${ }^{4} \mathrm{O}$ pensamento estruturalista tem sua origem na linguística estrutural desenvolvida por Ferdinand de Saussure na virada do século XIX para o século XX. Seus principais representantes foram: Claude Lévi-Strauss, Roland Barthes, Louis Althusser e Jacques Lacan.

${ }^{5} \mathrm{O}$ estruturalismo tem como principal precursor o linguista Ferdinand de Saussure, que considera que toda estrutura apresenta-se em forma de linguagem e seu sentido se expressa por meio da diferença dos diversos signos e dos significados a eles atribuídos.
} 
campo, não existe hierarquia entre as culturas, não existe nenhum critério transcendente pelo qual uma cultura possa ser julgada superior à outra. Eis o seu impulso inicial, ressaltando que cada cultura é resultado das diferentes formas com que seus membros, dadas suas próprias condições históricas e ambientais, intervêm nesses espaços (SILVA, 2011).

Entre as várias vertentes, na perspectiva crítica do multiculturalismo, a diferença é resultado de relações de poder. Logo, uma proposta pedagógica inspirada nessa concepção analisa os processos pelos quais as diferenças são produzidas por meio de relações assimétricas e desiguais. Além de incluir o estudo das práticas corporais pertencentes a grupos distintos, promove uma reflexão sobre a razão de algumas serem legitimadas socialmente, enquanto outras são desprestigiadas.

Outra teoria pós-crítica que oferece ferramentas para compreender a atualidade são os Estudos Culturais. Os trabalhos baseados nesse campo teórico renovaram a concepção de cultura e serviram de sustentação teórica e metodológica à premissa de que inexistem, em termos culturais, diferenças entre as chamadas grandes obras literárias e aquelas relacionadas às manifestações de grupos subjugados, tais como os pertencentes às classes operárias.

Historicamente, os Estudos Culturais sofreram influências de variadas correntes. Escosteguy (2010) explica que o amparo inicial no marxismo foi importante para analisar a interface cultura e economia. Apesar da crítica ao reducionismo e ao economicismo e a contestação do modelo de base-superestrutura, a perspectiva marxista contribuiu para os Estudos Culturais ao compreender a "autonomia relativa" da cultura, o que significa que ela não é dependente das relações econômicas, nem tampouco seu reflexo, mas sofre consequências que não devem ser desprezadas.

Nos anos 1970, segundo Hall (2009), o debate promovido pelos Estudos Culturais deslocou-se da perspectiva marxista para aspectos relacionados aos conceitos de ideologia e hegemonia de Antonio Gramsci. Sob influência do filósofo italiano, o projeto político dos Estudos Culturais incluiu o conceito de "intelectual orgânico", passando a defender que o trabalho teórico intelectual e a ação política são inseparáveis. A produção intelectual não deixa de ser uma prática política. No princípio da década de 1980, dá-se o início da internacionalização dos Estudos Culturais, com a influência dos franceses Michel Foucault, Michel de Certeau, Pierre Bourdieu, entre outros. O predomínio do marxismo cede lugar ao pós-estruturalismo, gerando novos deslocamentos e rupturas dentro do campo.

Uma das mais importantes mudanças decorreu da influência feminista (HALL, 2009). A leitura dos processos identitários baseada na classe social foi acrescida de aspectos como o entendimento da questão do pessoal como política, a expansão radical da noção de poder, a centralidade nas questões de gênero e sexualidade para compreender o próprio poder, a subjetividade e o sujeito como centrais na prática teórica, além da reabertura para a psicanálise. Também eclodiram críticas pautadas em questões étnicas, de política racial, resistência ao racismo e política cultural.

Como ressalta Escosteguy (2006), os Estudos Culturais foram se transformando, mudando sua base fundamental, de modo que a classe deixou de ser o conceito crítico central, passando a ser mais uma variável nas análises. Em relação a essas transformações, Hall (2009) considera que a "virada linguística" descentrou o caminho dos Estudos Culturais. A emergência da discursividade desencadeou a necessidade de repensar questões de cultura através das metáforas da linguagem e da textualidade.

O campo dos Estudos Culturais permite um olhar diferenciado para a pedagogia. Entendida como artefato cultural, uma proposta de ensino é um campo de luta em torno da significação e da identidade, em que diferentes grupos sociais tentam estabelecer sua hegemonia. Tanto a ação didática como os conteúdos são construções sociais, encontram-se imersos nas relações de poder que incluíram determinados saberes e excluíram outros (SILVA, 2011). 
Os Estudos Culturais inspiram o ensino da Educação Física a apagar fronteiras entre cultura popular e acadêmica, ou ainda, entre cultura de elite e cultura de massa, buscando abalar a concepção que a produção do conhecimento pertence ao curso natural da história e sinalizar que tanto os conhecimentos oriundos das comunidades escolares quanto os advindos dos setores em vantagem devem ser legitimados. Uma proposta influenciada pelos Estudos Culturais equipara todas as práticas corporais sem qualquer separação entre o conhecimento tradicionalmente considerado como escolar e o conhecimento cotidiano.

\section{As teorias pós-críticas e a cultura corporal}

As contribuições das teorias pós-críticas acima arroladas para o ensino da Educação Física encontram-se documentadas em vários estudos ${ }^{6}$, resta identificar suas influências na maneira de conceber a cultura corporal. De forma resumida, é possível dizer que à concepção de cultura influenciada pelo materialismo dialético e disseminada pelas teorias críticas são acrescidas as noções de discurso e identidade, concretizadas no entendimento de cultura como campo de lutas atravessado por relações de poder que atuam na validação de determinados significados em detrimento de outros.

Vistas sob esse prisma, as práticas corporais adquirem o status de textos culturais cujos significados são fruto do embate entre grupos e setores da sociedade (NEIRA; NUNES, 2006). Em certo contexto, uma modalidade esportiva pode ser produzida discursivamente como feminina e, em outro, vista como masculina (é o caso do futebol no Brasil e nos Estados Unidos); uma dança popular pode ser desterritorializada e, em seguida, apropriada por membros da elite (tome-se, como exemplo, o forró universitário) e, finalmente, uma luta tida como prática marginal e desprestigiada num momento pode, em outra época, ter seu sentido relacionado a um grande espetáculo (a transição experimentada pelo UFC é uma boa ilustração do fato). Nas situações mencionadas, o que definiu uma posição ou outra não foi algo próprio, específico da prática corporal em tela, mas sim o resultado de ações e discursos que legitimaram o significado que interessava aos grupos mais poderosos.

Compreender a cultura corporal como um terreno de disputa entre setores da sociedade implica a adoção de atividades de ensino que proporcionem a identificação das forças em atuação e de quem são os interessados. Além disso, é desejável a organização e o desenvolvimento de situações didáticas que possibilitem aos estudantes conhecer discursos e posicionamentos antagônicos com relação à prática corporal objeto de estudo e seus representantes. Quando as teorias pós-críticas inspiram o conceito de cultura corporal, as experiências pedagógicas da Educação Física combatem a fixação dos significados por meio da hibridização discursiva.

Evidentemente, o olhar pós-crítico sobre a cultura corporal é avesso a manuais técnicos de aplicação ou sequências de atividades predefinidas. Não há como dizer "faça assim, assim e assim, e se torne pós-crítico". Tampouco se espera que essa visão adquira hegemonia na área. Isso seria pura contradição. Uma atuação didática que se coaduna com a ideia de que a cultura corporal é um território contestado requer uma certa configuração do ambiente institucional. Em primeiro lugar, todos os envolvidos têm de reconhecer o trabalho pedagógico como um conjunto de experiências pautadas na incerteza dos resultados. A análise cultural das práticas corporais e a sua reconstrução crítica são o eixo principal das ações docentes e discentes. Tanto os significados atribuídos à brincadeira, à dança, à luta, ao esporte e à ginástica objetos de estudo quanto os dispositivos que influenciaram a sua produção têm de ser discutidos, assim como a vivência e a recriação corporal. Colocado de outra maneira, o exame

\footnotetext{
${ }^{6}$ Chaim Júnior (2007), Lima (2007 e 2015), Macedo (2010), Escudero (2011), Françoso (2011), Neira (2010, 2011 e 2013), Oliveira (2012), Souza (2012), Lins Rodrigues (2013 e 2015), Mazzoni (2013), Aguiar (2014), Leite (2015) e Eto (2015).
} 
da teia de relações que envolvem uma dada prática corporal não pode se divorciar da experiência de elaboração por parte dos estudantes.

O ensino da Educação Física baseado nas teorias pós-críticas consiste na promoção do diálogo entre as múltiplas lógicas que atravessam os diferentes grupos que coabitam a sociedade e que veiculam seus significados por meio da cultura corporal. Assim como qualquer outro, esse conceito está em contínua reconstrução no jogo das relações de poder. Transformadas em objeto de estudo, as práticas corporais são vistas como artefatos culturais gerados no campo de disputas da cultura mais ampla, é o que lhes imprime os signos dos grupos sociais em que são criadas e recriadas. Se estudantes e professores puderem entendê-las dessa forma, terão dado um passo decisivo para compreender o que acontece na sociedade.

\title{
CLASHES AROUND THE BODY CULTURE CONCEPT: GENESIS AND TRANS- FORMATION
}

\begin{abstract}
This mapping describes and analyzes the influences suffered by the concept of body culture since its inception. Designed in political openness context and inspired by the critical theories, it was decisive in the paradigm shift that the teaching of physical education experienced from the 1980s. Softened by anthropological studies and subsequently weakened by the neoliberal discourse of the 1990s, the notion of body culture had its strength renewed in the twenty-first century through the contribution of post-critical theories of education.
\end{abstract}

Keywords: Physical Education. Body Culture. Critical Theories.

\section{LOS ENFRENTAMIENTOS EN TORNO AL CONCEPTO DE CULTURA CORPO- RAL: GÉNESIS Y TRANSFORMACIONES}

\begin{abstract}
Resumen
Este mapeo describe y analiza las influencias sufridas por el concepto cultura corporal desde su creación. Diseñado en el contexto de la apertura política, se inspiró en las teorías críticas y fue decisivo en la transformación del paradigma que la enseñanza de la educación física experimentó desde la década de 1980. Amortecida por los estudios antropológicos y, más tarde, debilitada por el discurso neoliberal de la década de 1990, la noción de cultura corporal tuvo sus fuerzas renovadas en el siglo XXI a través de la contribución de las teorías post-críticas de la educación.
\end{abstract}

Palabras clave: Educación Física. Cultura Corporal. Teorías Post-críticas.

\section{Referências}

AGUIAR, C. A. Educação Física no município de São Paulo: aproximações e distanciamentos com relação ao currículo oficial. 2014. 187 f. Dissertação (Mestrado em Educação) Faculdade de Educação, Universidade de São Paulo, São Paulo, 2014.

BRACHT, V. A criança que pratica esporte respeita as regras do jogo... capitalista. Revista Brasileira de Ciências do Esporte, Campinas. v. 7, n. 2, p. 62-68, 1986. 
Educação Física: a busca da autonomia pedagógica. Revista da Fundação de Esporte e Turismo, Maringá, v.1, n. 2, p. 2-19, 1989.

A constituição das teorias pedagógicas da Educação Física. Cadernos Cedes, ano XIX, no 48, p. 69-88, ago. 1999.

BRASIL. Ministério da Educação e Desporto. Secretaria da Educação Fundamental. Parâmetros Curriculares Nacionais Primeiro e Segundo Ciclos do Ensino Fundamental - Educação Física. Brasília: MEC/SEF, 1997.

Ministério da Educação e Desporto. Secretaria da Educação Fundamental. Parâmetros Curriculares Nacionais Terceiro e Quarto Ciclos do Ensino Fundamental - Educação Física. Brasília: MEC/SEF, 1998.

Ministério da Educação e Desporto. Secretaria da Educação Média e Tecnológica. Parâmetros Curriculares Nacionais: Ensino Médio. Brasília: Ministério da Educação, 1999.

CHAIM JÚNIOR, C. I. Cultura corporal juvenil da periferia paulistana: subsídios para a construção de um currículo de Educação Física. 2007. 99 f. Dissertação (Mestrado em Educação) - Faculdade de Educação, Universidade de São Paulo. Faculdade de Educação, São Paulo, 2007.

DAOLIO, J. Da cultura do corpo. Campinas: Papirus, 1995.

Cultura: Educação Física e futebol. Campinas: Editora da Unicamp, 1997.

DIECKERT, J. et al. Elementos e princípios da Educação Física. Uma antologia. Rio de Janeiro: Ao Livro Técnico, 1985.

ESCOSTEGUY. A. C. D. Estudos Culturais: uma introdução. In: SILVA. T. T. O que é, afinal, Estudos Culturais? Belo Horizonte: Autêntica, 2006. p. 113-166.

Cartografias dos Estudos Culturais: uma versão latino-americana. Belo Horizonte: Autêntica, 2010.

ESCUDERO, N. T. G. Avaliação da aprendizagem em Educação Física na perspectiva cultural: uma escrita autopoiética. 2011. 174f. Dissertação (Mestrado em Educação) - Faculdade de Educação, Universidade de São Paulo, São Paulo, 2011.

ETO, J. Desconstruindo o futebol e a erotização da dança: uma experiência de Educação Física na escola do campo de Matacavalo. 2015, 165 f. Tese (Doutorado em Educação) - Faculdade de Educação, Universidade de São Paulo, São Paulo, 2015.

FERREIRA, V. L. C. Prática da Educação Física no $1^{0}$ grau. São Paulo: Ibrasa, 1987.

FRANÇOSO, S. Cruzando fronteiras curriculares: a Educação Física no enfoque cultural na ótica de docentes de escolas municipais de São Paulo. 2011. 252 f. Dissertação (Mestrado em Educação) - Pontifícia Universidade Católica de São Paulo, São Paulo, 2011.

GRAMORELLI, L. C. O impacto dos PCN na prática dos professores de Educação Física. 2007. Dissertação (Mestrado em Educação) - Faculdade de Educação, Universidade de São Paulo, São Paulo, 2007. 
A cultura corporal nas Propostas Curriculares Estaduais de Educação Física: novas paisagens para um novo tempo. Tese (Doutorado em Educação) - Faculdade de Educação, Universidade de São Paulo, São Paulo, 2014.

HALL, S. A identidade cultural na Pós-modernidade. Rio de Janeiro: DPA, 2006.

2009.

Da diáspora: identidades e mediações culturais. Belo Horizonte: Editora UFMG,

LEITE, C. M. Potencialidades de produção subjetiva do professor de Educação Física escolar em direção à perspectiva cultural: a experiência no currículo do estado de São Paulo. 2015.183 f. Tese (Doutorado em Educação) - Faculdade de Educação, Universidade de São Paulo, São Paulo, 2015.

LOPES, A. C.; MACEDO, E. Teorias do currículo. São Paulo: Cortez, 2011.

LIMA, M. E. A Educação Física no projeto político-pedagógico: espaço de participação e reconhecimento da cultura corporal dos alunos. 2007. 133 f. Dissertação (Mestrado em Educação) - Faculdade de Educação, Universidade de São Paulo, São Paulo, 2007.

Nas malhas da rede: o currículo cultural de Educação Física em ação. 2007. 222 f. Dissertação (Doutorado em Educação) - Faculdade de Educação, Universidade de São Paulo, São Paulo, 2015.

LINS RODRIGUES, A. C. Corpos e culturas invisibilizados na escola: racismo, aulas de Educação Física e insurgência multicultural. 2013. 235 f. Tese (Doutorado em Educação) Faculdade de Educação, Universidade de São Paulo, 2013.

Culturas negras no currículo da Educação Física. Relatório de Pesquisa. Faculdade de Educação, Universidade de São Paulo, 2015.

MACEDO, E. E. de. Educação Física numa perspectiva cultural: análise de uma experiência em creche. 2010. 134 f. Dissertação (Mestrado) - Faculdade de Educação, Universidade de São Paulo, São Paulo, 2010.

MAZZONI, A.V. "Eu vim do mesmo lugar que eles": relações entre experiências pessoais e uma educação física multiculturalmente orientada. 2013. 182 f. Dissertação (Mestrado em Educação) - Faculdade de Educação, Universidade de São Paulo, São Paulo, 2013.

MEDINA, J. P. S. A Educação Física cuida do corpo e... "mente". Campinas: Papirus, 1983.

NEIRA, M. G. Análises das representações dos professores sobre o currículo cultural da Educação Física. Interface, Botucatu, v. 14, n. 35, dez. 2010b, p. 783-795.

A reflexão e a prática do ensino - Educação Física. São Paulo: Blucher, 2011a.

O currículo cultural da Educação Física em ação: a perspectiva dos seus autores, 2011. 330f. Tese (Livre-Docência) - Faculdade de Educação, Universidade de São Paulo, São Paulo, 2011b. 
A seleção dos temas de ensino do currículo cultural da Educação Física. Revista Educación física y deporte, Medellín (Colômbia), v. 32, p. 1421-1430, 2013.

NEIRA, M. G.; NUNES, M. L. F. Pedagogia da cultura corporal: crítica e alternativas. São Paulo: Phorte, 2006.

Educação Física, currículo e cultura. São Paulo: Phorte, 2009.

OLIVEIRA, L. P. O ingresso na carreira de professores de Educação Física: currículo e atuação docente. 2012. 133f. Dissertação (Mestrado em Educação) - Programa de PósGraduação em Educação, Universidade Nove de Julho, 2012.

SAVIANI, Dermeval. Pedagogia históricocrítica: Primeiras aproximações. 2. ed. São Paulo: Cortez/Autores Associados, 1991.

SOUZA, M. M. N. "Minha história conto eu": multiculturalismo crítico e cultura corporal no currículo da Educação Infantil, 2012. 291 f. Dissertação (Mestrado em Educação) - Faculdade de Educação, Universidade de São Paulo, São Paulo, 2012.

SOUZA JÚNIOR, M. et al. Coletivo de Autores: a cultura corporal em questão. Revista Brasileira de Ciência do Esporte, Florianópolis, v. 33, n.2, p391- 411, abril/jun. 2011.

SILVA. T. T. Documentos de Identidade: uma introdução às teorias do currículo. Belo Horizonte: Autêntica, 1999.

SOARES, C. L. et al. Metodologia do ensino de Educação Física. São Paulo: Cortez, 1992.

VIEIRA. F. C. T. A disciplina Educação Física nos Parâmetros Curriculares Nacionais para o terceiro e quarto ciclos do Ensino Fundamental: inovações e permanências. 2010. Dissertação (Mestrado em Educação) - Pontifícia Universidade Católica de São Paulo, São Paulo, 2010.

Recebido em: 18/10/2015

Revisado em: 27/05/2016

Aprovado em: 21/12/2016

Endereço para correspondência:

mgneira@usp.br

Marcos Garcia Neira

Universidade de São Paulo

Butantã, São Paulo - SP

03178-200 